\title{
EL ZIGZAG HUSSERLIANO
}

por Javier San Martin

Quisiera dar las gracias a los organizadores por haberme invitado a participar en este acto, que debe rendir homenaje a un pensador que supo mantener la antorcha de aquel pensamiento crítico que siempre está pensando en un futuro inserto en el presente; y que lo supo hacer en un lugar en el que todo incita a pensar en el pasado. Acabo de pasar una Semana en Burgos y he podido ver hasta qué punto tuvo que ser diffcil para Luis Martín Santos mantener la antorcha del pensamiento crítico en ese ambiente, en esa Castilla "llena de implicaciones, de negaciones, incluso de amenazas", de que nos habla en el cap. $7^{1}$. Desde esa perspectiva es fácil entender una línea que recorre la comprensión de la fenomenología por parte de Luis Martín Santos: a saber el hecho de que el fenomenólogo Husserl es un "filosofo tachado" (p. 89 s.).

Quisiera seleccionar en esta presentación algunos puntos de la concepción de la fenomenología por parte de Luis Martín Santos que me parecen dignos de ser señalados, sobre todo porque tienen una extraña actualidad, extraña, porque viniendo de un pensador recluído en gran medida en Burgos, chocan por su novedad y actualidad.

1. Ante todo me gustarfa comentar brevemente la evaluación que Luis Martín Santos hace de la fenomenologfa, por un lado su visión de la

\footnotetext{
${ }^{1}$ El zigzag husserliano, edición preparada por Ana Lucas, Editorial Endymion, Madrid, 1991, pag. 63.
} 
relación de la fenomenología con la filosofía actual. Para Martín Santos la fenomenología es la filosofía secreta de nuestro tiempo, como tituló uno de sus últimos trabajos. A la altura de 1988, cuando está hecha esta afirmación, es sin lugar a dudas valiente, pues no se puede olvidar la situación real de la fenomenología, sobre todo en nuestro País, donde hacer fenomenologia implicaba ser estigmatizado con la marca filosófica de cavernícola, retrogrado, alejado del mundo etc. No me corresponde ahora evaluar el acierto de esta apreciación de Martín Santos, porque sería en todo caso, se podrfa decir, parcial por mi parte. Pero merece la pena subrayar esa apreciación de Martín Santos respecto a lo que la fenomenología representa para la filosofía actual, porque, como él mismo lo ha tenido que experimentar, el creador de la fenomenología es un filósofo tachado (p. 89), pues, nos dice, "si figura en los programas universitarios, no se le explica o se pasa sobre él como sobre ascuas para llegar cuanto antes a sus "brillantes" disć́pulos". Husserl es en ese sentido el autor tachado de los programas. Obviamente, eso es así porque es el autor o la filosofía tachada del mundo actual. Es sumamente interesante esta anotación, porque esa actitud es generalizada, incluso en aquellos casos cuyo pleno sentido sólo es asequible teniendo en cuenta la propia fenomenología. Como es el caso, p.e. de Ortega, quien sólo puede ser entendido en la medida en que se lo lee desde el movimiento fenomenológico que él asmila y desarrolla. Pero incluso para Ortega Husserl no. deja en cierta manera de ser un filósofo tachado. En mi opinión esta apreciación de Martín Santos merece ser tenida ya, nada más ser dada a la luz, como una frase que se popularizará en nuestra ámbito.

Más ¿por qué es una filosoffa tachada, a pesar de ser la filosofia secreta de nuestro tiempo? y esta serfa una tercera nota en la evaluación de Martín Santos. Pues otra vez Luis Martín Santos nos da respuesta certera a esa pregunta, y una respuesta atinada, precisa, de 
profunda penetración psicológica: porque Husserl es un "filósofo maldito" (p. 27) que nunca nos deja en paz, porque toda incursión en él es necesariamente una incursión en la provisionalidad, una provisionalidad desesperante, incompatible con la sensualidad reposada de quien ha logrado la verdad. En ese sentido es una filosofía autoagresiva (p. 27). En Husserl todo es un camino de interpretaciones que se remiten a otras interpretaciones de interpretaciones, en el que nunca encontramos reposo, a pesar de que el propio Husserl tuviera como meta única la búsqueda de la certeza absoluta. Husserl es un filósofo que nos crucifica, con el que "Los interrpretes sserios" (y entrecomilla la palabra 'serios'), se sienten «crucificados»" (p. 86). Esta expresión, a mi entender también muy afortunada, sólo la puede pensar quien se ha dedicado al estudio de Husserl con toda intensidad, seriedad y convencimiento de la importancia de ese trabajo para la configuración del pensamiento propio. Quien no haya accedido así a Husserl no se siente crucificado, porque lo abandona. Digo esto porque me parece que nos indica el lugar desde el que hay que entender la filosoffa y la vida de Luis Martín Santos.

2. Me interesa ahora resaltar una serie de ideas recogidas aqur y allá sobre el tipo de filosoffa que es la fenomenologra para Luis Martín Santos, ya que en ellas se vehicula su aportación más interesante, y por supuesto en España profundamente novedosa, la fenomenologra como una filosoffa que nos obliga a mirar el mundo de una manera distinta, en la que tiene que conjuntarse con el marxismo, pero de modo que también éste debe dejarse fecundar por la fenomenología.

Empecemos citando ese precioso texto con el que Ana Lucas ha abierto el libro, ese texto procedente de ese ensayo de descripción fenomenológica tan bella de las páginas 59-62, y que trata de describir 
la telefosis, la teleología husserliana, necesaria para mantener el movimiento real de la intencionalidad (p. 60). Pero Luis Martín Santos convierte la idea de teleíosis en el centro de la fenomenología como modo de vida, con sus peligros y su necesidad, porque sin ella nos perdemos en lo sustantivizado, devorador de todo movimiento humano. Sólo con ella podemos vivir en el movimiento referido a un horizonte, que sin embargo no podemos sustantivizar. Presumiblemente en este capitulo 7 se encuentran algunas de las ideas centrales de la obra fenomenológica de Martín Santos, pues en él se expone con claridad lo que representa el cambio de perspectiva que la fenomenología supone, ya que aunque en la teleología siempre somos arrastrados hacia el objeto trascendente, "la fenomenología no permite salir del interior de la intencionalidad"; este sería el efecto de la propia epojé, que de esa manera se convierte en la gran palanca para un cambio de perspectiva en la mirada, un cambio de perspectiva radical, a partir del cual veremos que todo lo que nos rodea está unido por lazos invisibles; que entre nosotros y la realidad no hay ninguna cesura, porque la realidad es el correlato de la intencionalidad.

Desde esta perspectiva es la epojé fenomenológica la que nos tiene que correr el velo que encubre la realidad y que ha convertido una realidad fluida, resultado de nuestra presencia en el mundo, en algo petrificado, sustancializado, trascendente. La epojé descorre ese velo, revelando la realidad auténtica, a la que, por otra parte, nos referimos siempre en nuestra vida. Por eso la epojé, a decir de Luis Martín Santos, tiene que ser sincrónica con la crítica marxiana; aquella "intenta correr el velo teórico que envuelve la realidad"; ésta "«denuncia toda teoría como un compromiso de los intereses de una clase y de las presiones que provienen del amor a la libertad, o dicho de otra forma, el conflicto entre los intereses particulares y el interés humano" (p. 69). 
3. Llama la atención el esfuerzo de Martín Santos por sistematizar la fenomenología en las clásicas trfadas de la dialéctica. Ya sólo desde esa perspectiva es interesante y didáctica su aportación. No porque eso nos facilite hoy en día la comparación de la fenomenología con la dialéctica marxiana, que se da más a nivel de la función crítica que la fenomenología desempeña y de la vuelta al mundo inmediato de la corporalidad viva, sino porque detrás de esa sistematización triádica se descubre fácilmente la marcha misma de la fenomenología husserliana, que se hace francamente diffcil de entender, si no se la concibe desde alguna sistematicidad de ese tipo. El "tríptico dialéctico y temático" (p. 18), como le llama Ana Lucas en el excelente prólogo que ha escrito para el libro, se compone de cuatro triadas de conceptos, uno se refiere a las fases temporales de la fenomenología como trascurso vital, en el que se da una aurora, una madurez y un crepúsculo. El segundo grupo triádico da contenido a cada uno de esos momentos, el primero es el momento de la reducción eidética; el segundo es el momento de la reducción trascendental y el tercero sería el momento de la recuperación de lo real en torno al concepto de mundo de la vida. El primer momento serfa típicamente analítico, de análisis de lo que se da delante, sea ésto una realidad ideal o real. El segundo momento es es trascendental, en él se busca la vida que sostiene lo objetivo, las trascendencias. El tercer momento serfa el de la vuelta a lo real, pero a una realidad ya trabajada por la reducción, por la teleología de la intencionalidad, una realidad ya vista desde el nuevo modo de ver propio de la fenomenología. Puesto en términos dialécticos clásicos, el primer momento es el de la afirmación o tesis; en él se pone la realidad tal como es, se afirma la objetividad del ser. El segundo momento tiene como función negar esa objetividad en cuanto lo absoluto; por eso es el momento de la antítesis en el que 
la objetividad queda referida a la subjetividad, a la intencionalidad. Pero no se entendería el verdadero sentido de ese segundo momento si no negamos la negación, recuperando la tesis, si bien se trata ya de una tesis trascendentalmente aclarada, una tesis a la que se le ha descubieto el movimiento subterráneo teleológico del que depende.

Esta concepción global de la fenomenologfa propuesta por Luis Martín Santos es extraordinariamente didáctica para entender la fenomenologfa pero es que además, (con algunas ligeras matizaciones, que sólo a través de la lectura de muchos textos de Husserl, algunos de ellos publicados en años muy posteriores a los de la elaboración de la tesis por parte de Martín Santos, y otros incluso no publicados), coincide globalmente con la marcha general de la obra de Husserl, incluso con los lugares en los que estuvo Husserl, pues el primer momento es el momento de la Universidad de Halle, que termina con las Investigaciones logicas. El segundo momento es fundamentalmente el de Gotinga, que termina con las Ideas relativas a una fenomenologla pura y para una filosofia fenomenologica. El tercer momento se corresponde globalmente con los amplios desarrollos de la fenomenologfa por parte de Husserl durante su estancia en Friburgo y que termina con la obra de más actualidad, que es La crisis de las ciencias europeas.

4. Por fin, quiero señalar algo decisivo en la fenomenologla y que Luis Martín Santos ha sabido ver hasta el punto de dar el título a su libro, con lo que resalta el carácter central del zigzag. No me voy a meter excesivamente en el tema, porque rebasaría el tiempo que me ha asignado. Sólo quiero decir que en la fenomenologfa esos tres momentos no son independientes, todos se remiten mutuamente y no pueden ni siquiera ser sistematizados sino yendo de uno al otro y viceversa. Cualquier interpretación que no se base en el zigzag, 
fallaría radicalmente en la comprensión de la fenomenología. Desgraciadamente ese ha solido ser el caso, incluso entre intérpretes relativamente cercanos a los textos de Husserl. $Y$ es que en realidad cuesta mantener la actitud dialéctica que nos impide detenernos en ninguna de las fases, porque cada una de ellas se remite a la otra. No quiero seguir insistiendo en esto. Sólo quiero señalar que esta conclusión de Martín Santos le da, sin lugar a dudas, un puesto decisivo en la aportación a la fenomenología española y que deberá ser tenido en cuenta y desarrollado en el futuro. 